\title{
A postoperative comparison of high-flow nasal cannula therapy and conventional oxygen therapy for esophageal cancer patients
}

\author{
Mei Xia ${ }^{1}$, Weina $\mathrm{Li}^{1}$, Jie $\mathrm{Yao}^{2}$, Ying Jin ${ }^{3}$, Gaoli Du ${ }^{1}$, Qianfeng $\mathrm{Xu}^{1}$, Xing $\mathrm{Yi}^{1}$, Xiaoxia $\mathrm{Nv}^{1}$, Yi $\mathrm{Wu}^{2}$, \\ Ping $\mathrm{He}^{4}$, Wei Wu ${ }^{1}$ \\ ${ }^{1}$ Thoracic Surgery Department, Southwest Hospital, the First Hospital Affiliated to Army Medical University, Chongqing, China; ${ }^{2}$ Institute of \\ Digital Medicine, Biomedical Engineering College, Army Medical University, Chongqing, China; ${ }^{3}$ Health medicine Department, 920 Hospital, \\ Kunming, China; ${ }^{4}$ Cardiac Surgery Department, Southwest Hospital, the First Hospital Affiliated to Army Medical University, Chongqing, China \\ Contributions: (I) Conception and design: M Xia, P He, W Wu; (II) Administrative support: W Wu, P He, Y Wu; (III) Provision of study materials or \\ patients: M Xia, J Yao, Y Wu, P He, W Wu; (IV) Collection and assembly of data: W Li, J Yao, Y Jin, G Du, Q Xu, X Yi, X Nv; (V) Data analysis and \\ interpretation: Y Wu, W Wu, P He; (VI) Manuscript writing: All authors; (VII) Final approval of manuscript: All authors. \\ Correspondence to: Wei Wu. Thoracic Surgery Department, Southwest Hospital, the First Hospital Affiliated to Army Medical University, Chongqing \\ 400038, China. Email: wuweiyahoo@sohu.com; Ping He. Cardiac Surgery Department, Southwest Hospital, the First Hospital Affiliated to Army \\ Medical University, Chongqing 400038, China. Email: yhp0130@sina.com; Yi Wu. Institute of Digital Medicine, Biomedical Engineering College, \\ Army Medical University, Chongqing 400038, China. Email: wuy1979@tmmu.edu.cn.
}

Background Hypoxaemia in post-surgical patients of esophageal cancer (EC) is common in thoracic departments. However, few studies have investigated the role of high-flow nasal cannula (HFNC) compared with conventional oxygen therapy (COT).

Methods: A retrospective study was implemented to enroll hypoxemic patients after esophagectomy who were treated by HFNC or COT immediately after extubation between January 2019 and December 2019. We compared the effect of HFNC or COT in patients regarding the vital signs and arterial blood gases, the incidence of anastomotic leakage, postoperative pulmonary complications (PPCs), sore throat/nose, and reintubation, length of stay, and sputum production. We also $3 \mathrm{D}$ reconstructed the postoperative chest CT, and compared the amount of lung volume loss caused by PPCs (pneumothorax, atelectasis, pulmonary consolidation and pleural effusion) between the two groups.

Results: Compared to patients in COT group, sore throat/nose in HFNC group was lower, the sputum production was higher, and the total hospital stay was shorter. Compared to COT, HFNC treatment decreased systolic blood pressure (SBP) at day 1, diastolic blood pressure (DBP) at day 1-4, and heart rate (HR) at day 2-4, increased arterial partial pressure of oxygen $\left(\mathrm{PaO}_{2}\right)$ at day 1-4, and arterial oxygen saturation $\left(\mathrm{SaO}_{2} \%\right)$ at day 1-2. In addition, the rate of PPCs and anastomotic leakage in HFNC group were lower than those in COT group. Compared to COT, HFNC treatment significantly decreased the amount of lung volume loss caused by PPCs.

Conclusions: HFNC can improve the hypoxemia of patients after esophagectomy, increase the flow of sputum, reduce the incidence of PPC and anastomotic leakage.

Keywords: High-flow nasal cannula (HFNC); esophageal cancer (EC); post-operation; hypoxaemia

Submitted Aug 03, 2020. Accepted for publication Nov 27, 2020.

doi: 10.21037/apm-20-1539

View this article at: http://dx.doi.org/10.21037/apm-20-1539

(c) Annals of Palliative Medicine. All rights reserved. 


\section{Introduction}

Esophageal cancer (EC), with its high risk of metastases and recurrence, is the 4th highest deadliest cancer among all cancer types and one of the most prevalent in China (1-3). One of the effective treatment options for EC patients is radical esophagectomy, though it is known to be associated with a high mortality rate (4), which might be due to several factors. EC patients usually suffer from compromised digestive and immune system; they may also deal with tobacco and alcohol addiction. On top of these conditions, they also have to recover from the severe injuries they suffered during the operation, such as long operation time and vast area of trauma that often involves neck, chest, and abdomen. Moreover, patients are often known to develop multiple postoperative pulmonary complications (PPCs) and anastomotic leakages (5). During the past few years, multiple large-sample prospective clinical studies reported that highflow nasal cannula (HFNC) could reduce the incidence of PPCs while others disagreed, and Pennisi reported (6) similar incidence of PPCs in their post-lobectomy patients. In addition, several institutions have also applied HFNC to cardiac surgery patients and proven that HFNC can improve the comfort of patients after cardiac surgery and reduce the need to upgrade respiratory support (7). However, few studies have analyzed the effectiveness of postoperatively HFNC to the treatment of hypoxemia for EC patients. In the present study, we aimed to determine whether postoperative application of HFNC is superior to conventional oxygen therapy (COT) for EC patients.

We present the following article in accordance with the STROBE reporting checklist (available at http://dx.doi. org/10.21037/apm-20-1539).

\section{Methods}

\section{Patients selection}

We had compared HFNC with COT in parallel for 1 year until it totally replaced COT for hypoxemic patients in 2019 (HFNC was introduced into our Department in August 2019. Before that, COT was used in all patients after esophagectomy, and HFNC was used after that). The clinical data of those patients weaned from mechanical ventilation were collected from January 1, 2019 to December 31, 2019 after esophagectomy in the Thoracic Surgery Unit of our hospital.

Patients with postoperative hypoxemia were enrolled in the study. Postoperative hypoxemia was defined as
$100 \mathrm{mmHg} \leq$ arterial partial pressure of oxygen/fraction of inspiration oxygen $\left(\mathrm{PaO}_{2} / \mathrm{FiO}_{2}\right)<300 \mathrm{mmHg}$ after weaning from mechanical ventilation, as used previously. The hypoxemia was also diagnosed as arterial oxygen saturation $\left(\mathrm{SaO}_{2}\right)<92 \%$, respiratory rate $(\mathrm{RR})>30$ breath/min, without respiratory failure caused by other complications such as bleeding and heart failure. Patients were excluded from the study if they had (I) clinical history of underlying chronic obstructive pulmonary disease, (II) cardiogenic pulmonary edema, (III) tracheostomy, (IV) delirium, nausea and vomiting, (V) impaired consciousness or disorientation, (VI) hemodynamic instability, (VII) sudden cardiac arrest, (VIII) moderate to severe respiratory acidosis hypercapnia $(\mathrm{pH}$ $<7.30)$ combined with multiple organ dysfunctions. The study was conducted in accordance with the Declaration of Helsinki (as revised in 2013). The study was approved by the Ethical Committee of Southwest Hospital (IRB number: KY201846) and individual consent for this retrospective analysis was waived.

\section{Postoperative treatments}

Patients in the thoracic surgery ICU were placed on routine monitoring. In our practice, all hypoxemic patients eligible for inclusion were immediately treated after extubation with either COT or HFNC oxygen therapy. Patients in COT group received oxygen via either nasal prongs or facemasks with oxygen flow titrated by the bedside clinician to maintain a peripheral oxygen saturation $\left(\mathrm{SpO}_{2} \% \geq 95 \%\right)$. For patients wearing a nasal cannula or a simple face mask, each additional liter/min of oxygen added about 4 percentage points for the first 3 liters and only 3 percentage points for every liter thereafter to the desired $\mathrm{FiO}_{2} \%$. Patients in the HFNC (Optiflow ${ }^{\mathrm{TM}}$ Nasal High Flow; Fisher \& Paykel Healthcare, New Zealand) group received oxygen at an intial flow rate of 30 to $40 \mathrm{~L} / \mathrm{min}$ and $\mathrm{FiO}_{2} \%$ titrated (from $21 \%$ to $100 \%$ ) by the treating clinician to maintain $\mathrm{SpO}_{2} \%$ of $\geq 95 \%$. The gas temperature was set to $32-37{ }^{\circ} \mathrm{C}$ with a humidifier. Reintubation was determined by the treating physician based on the general intubation criteria, including increased RR, acute respiratory failure as well as patient intolerance.

\section{Data collection}

Patients' information including age, gender, body mass index (BMI), smoking index, pre-surgery forced expiratory volume in 1 second/forced vital capacity $\left(\mathrm{FEV}_{1} / \mathrm{FVC}\right)$, 


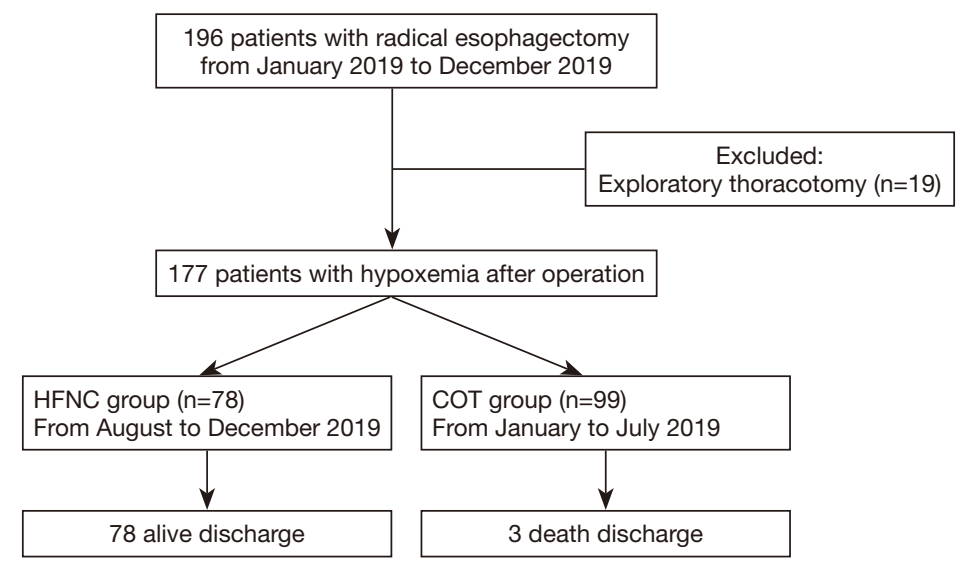

Figure 1 Patient flow chart. HFNC, high-flow nasal cannula; COT, conventional oxygen therapy.

operation time, tumor location, $\mathrm{Hb}, \mathrm{RR}, \mathrm{PaO}_{2}$ and thoracoscopic results were obtained from medical record review. The clinical outcomes after oxygen therapy were recorded and used as the primary outcomes to compare the differences between the two groups of patients. In detail, vital signs, arterial blood gases variables in 4 days (if acquired), anastomotic leakage or PPCs (PPCs were defined as atelectasis, suspected pulmonary infection, pleural effusion, and pneumothorax) from the first 10 days of oxygen therapy, sputum production for the first 3 days of oxygen therapy, in-hospital mortality rate, ICU length of stay, length of hospital stay, and events of sore throat/ nose and reintubation were recorded. There was no data missing.

\section{Image reconstruction and volume calculation}

On the 5 th day after operation, we reexamined the two groups of patients with chest CT. With Amira software, the normal lung, pneumothorax, pleural effusion, atelectasis and lung consolidation, and pleural effusion were segmented and $3 \mathrm{D}$ reconstructed, and then the $3 \mathrm{D}$ model was smoothed and simplified. We measured the lung volume loss which was caused by pneumothorax, atelectasis and pulmonary consolidation, and pleural effusion, and compared the lung volume loss between the two groups.

\section{Statistical analysis}

All statistical analyses were performed using SPSS 22.0. Continuous variables were expressed as mean \pm standard deviation (SD) or median [interquartile range (IQR)], and categorical variables were presented as $\mathrm{n}(\%)$. The differences of laboratory findings between groups were compared using $t$-test, Mann-Whitney $\mathrm{U}$ test, $\chi^{2}$ test, or Fisher's exact test as appropriate. Kaplan-Meier curves were also constructed to assess the probability of remaining patients who were free from PPCs after discontinuation of the allocated treatment. And $\mathrm{P}<0.05$ was considered statistically significant.

\section{Results}

\section{Baseline characteristics}

Of the total 196 patients admitted, 19 patients who underwent exploratory thoracotomy were excluded. The remaining 177 patients who underwent radical resection of esophageal carcinoma were enrolled. Among these 177 patients, 78 patients accepted HFNC therapy from August to December 2019, and 99 patients accepted COT from January to July 2019. Among these 99 patients, 3 patients died during the hospital stay. There was no significant difference between the two groups in factors such as intraoperative anesthesia, operation method and operator (Figure 1).

Although patients in HFNC group were older and had higher BMI, smoking index and RR than those in COT group, these differences were not statistically significant. Moreover, there were also no significant difference between the two groups of patients in gender, tumor location, preoperative $\mathrm{FEV}_{1} / \mathrm{FVC}, \mathrm{Hb}, \mathrm{PaO}_{2}$, operation time and thoracoscopic outcomes $(\mathrm{P}<0.05)$. These data indicate no significant differences between the two groups in baseline characteristics (Table 1). 
Table 1 Baseline patient demographic and clinical characteristics of the HFNC and COT groups

\begin{tabular}{|c|c|c|c|}
\hline Factors & COT $(n=99)$ & HFNC $(n=78)$ & $P$ \\
\hline Gender (male, \%) & 75 (79.79) & 67 (87.01) & 0.566 \\
\hline BMI $\left(\mathrm{kg} / \mathrm{m}^{2}\right)$ & $21.74 \pm 2.84$ & $23.66 \pm 2.44$ & 0.566 \\
\hline Smoking index & $483.11 \pm 416.98$ & $521.23 \pm 543.80$ & 0.103 \\
\hline The operation time (hr) & $3.85 \pm 1.22$ & $3.67 \pm 0.91$ & 0.605 \\
\hline Tumor location & & & 0.516 \\
\hline Upper & 39 & 35 & \\
\hline Middle & 24 & 21 & \\
\hline $\mathrm{RR}(\mathrm{bpm})$ & $15.61 \pm 3.14$ & $16.32 \pm 2.97$ & 0.683 \\
\hline $\mathrm{PaO}_{2} / 21 \%$ & $312.45 \pm 12.64$ & $308.26 \pm 16.22$ & 0.471 \\
\hline thoracoscope & $59(59.60)$ & $54(69.20)$ & 0.185 \\
\hline
\end{tabular}

Data are expressed as number (\%), mean \pm SD, or median (IQR), depending on variable distribution. HFNC, high-flow nasal cannula; COT, conventional oxygen therapy; BMI, body mass index; $\mathrm{FEV}_{1}$, forced expiratory volume in 1 second; FVC, forced vital capacity; RR, respiratory rate; $\mathrm{PaO}_{2}$, arterial partial pressure of oxygen; $\mathrm{SD}$, standard deviation; IQR, interquartile range.

\section{Comparison of the outcome events between the HFNC and COT groups}

The total hospital stay was $18.13 \pm 3.2$ days in the COT group and $14.47 \pm 2.6$ days in the HFNC group $(\mathrm{P}=0.041)$. The proportion of sore throat/nose was $5.13 \%(4 / 78)$ in the HFNC group and $16.2 \%(16 / 99)$ in the COT group $(\mathrm{P}=0.030)$. Sputum drainage in the first 3 days was $68.38 \pm 9.41 \mathrm{~mL}$ in the HFNC group and $56.12 \pm 6.93 \mathrm{~mL}$ in the COT group $(\mathrm{P}=0.032)$. Three patients $(3.0 \%)$ in the COT group developed severe pulmonary interstitial damage and died of fatal hypoxemia after endotracheal intubation and ventilator treatment, while no patient $(0.0 \%)$ in the HFNC group died. There was no significant difference in in-hospital mortality rate between the two groups $(\mathrm{P}=0.256)$. The reintubation rate was $8.1 \%(8 / 99)$ in the COT group and $3.8 \%(3 / 78)$ in the HFNC group during the treatment $(\mathrm{P}=0.351)$. The ICU length of stay was $2.51 \pm 0.87$ days in the COT group and $2.44 \pm 0.68$ days in the HFNC group $(\mathrm{P}=0.570)$ (Table 2).

\section{Comparison of patients' vital signs and arterial blood gases at different time points between HFNC group and COT group}

There was no significant difference between the two groups in terms of vital signs and arterial blood gases at the initiation of oxygen treatment. Compared to COT, HFNC treatment significantly decreased systolic blood pressure $(\mathrm{SBP})$ at day $1(\mathrm{P}<0.01)$, diastolic blood pressure (DBP) at day $1,2,3$, and $4(\mathrm{P}<0.01)$, and heart rate (HR) at day 2,3 , and 4, increased $\mathrm{PaO}_{2}$ at day $1,2,3$ and 4 , and $\mathrm{SaO}_{2} \%$ at day 1 and 2, while had no significantly different effects on temperature, $\mathrm{RR}, \mathrm{FiO}_{2} \%, \mathrm{PaCO}_{2}$ and $\mathrm{pH}(\mathrm{P}>0.05$ for all $)$ (Figure 2).

\section{PPCs and anastomotic leakage}

Kaplan-Meier plots of patients without anastomotic leakage and PPCs from initiation to day 10 after surgery indicated statistically significant between-group difference in the 
Table 2 Comparison of the outcome event between the HFNC and COT groups

\begin{tabular}{lccc}
\hline Factors & COT $(\mathrm{n}=99)$ & HFNC $(\mathrm{n}=78)$ & $\mathrm{P}$ \\
\hline Sore throat/nose & $16(16.20)$ & $4(5.13)$ & 0.030 \\
Sputum drainage (mL, in 3 days) & $56.12 \pm 6.93$ & $68.38 \pm 9.41$ & 0.032 \\
Reintubation & $8(8.10)$ & $3(3.80)$ & 0.351 \\
In-hospital mortality rate & $3(3.00)$ & $0(0.00)$ & 0.256 \\
ICU length of stay (days) & $2.51 \pm 0.87$ & $2.44 \pm 0.68$ & 0.570 \\
Length of stay (days) & $18.13 \pm 3.20$ & $14.47 \pm 2.60$ & 0.041 \\
\hline
\end{tabular}

Data are expressed as number (\%), mean \pm SD, depending on variable distribution. HFNC, high-flow nasal cannula; COT, conventional oxygen therapy; SD, standard deviation.

A
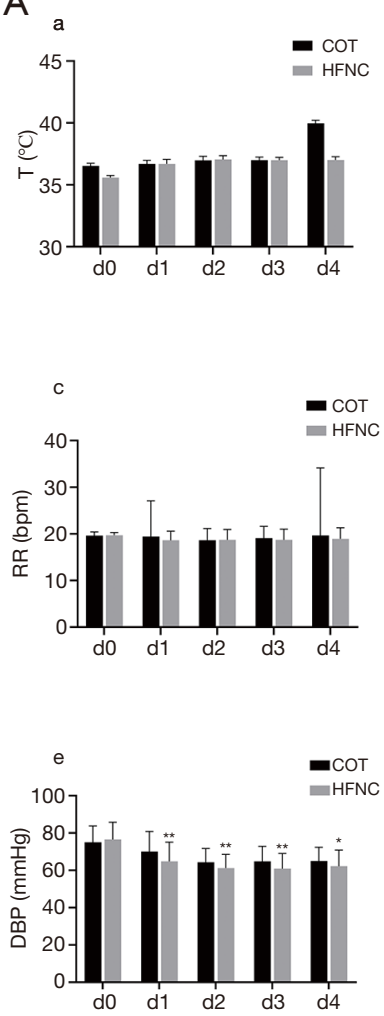

B

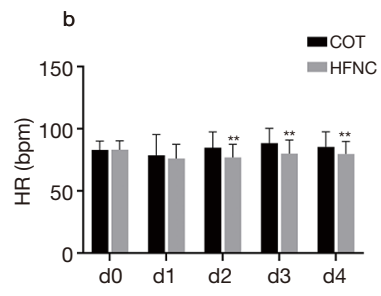

d
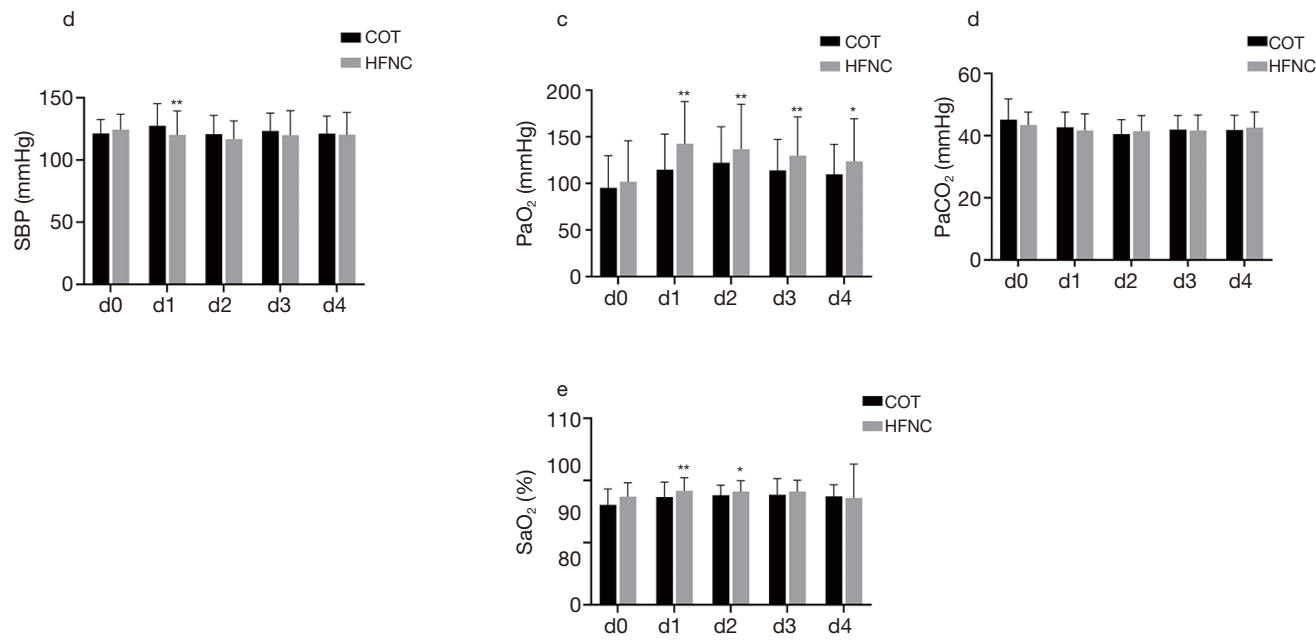

Figure 2 Comparison of variables between HFNC group and COT group in different time points. (A) Vital signs. (a) Auxillary temperature $\left({ }^{\circ} \mathrm{C}\right)$; (b) heart rate (HR); (c) respiratory rate (RR); (d) systolic blood pressure (SBP); (e) diastolic blood pressure (DBP). (B) Arterial blood gases. (a) Fraction of inspiration oxygen $\left(\mathrm{FiO}_{2} \%\right)$; (b) $\mathrm{pH}$; (c) arterial partial pressure of oxygen $\left(\mathrm{PaO}_{2}\right)$; (d) arterial partial pressure of carbon dioxide $\left(\mathrm{PaCO}_{2}\right)$; (e) arterial oxygen saturation $\left(\mathrm{SaO}_{2} \%\right)$. *, $\mathrm{P}<0.05 ;{ }^{* *}, \mathrm{P}<0.01$. HFNC, high-flow nasal cannula; COT, conventional oxygen therapy.

proportion of patients who remained free of any pulmonary complication during the 10-day postoperative followup. The PPCs occurred in 25 out of 99 (25.3\%, 95\% CI: $8.193-9.151 \%)$ patients in the COT group, while only occurred in 4 out of 78 (5.1\%, 95\% CI: 9.366-9.986\%) patients in the HFNC group $(\mathrm{P}<0.01, \log$-rank test). The anastomotic fistula occurred in 12 out of $99(12.1 \%, 95 \%$ CI: 9.006-9.722\%) patients in the COT group, while only 


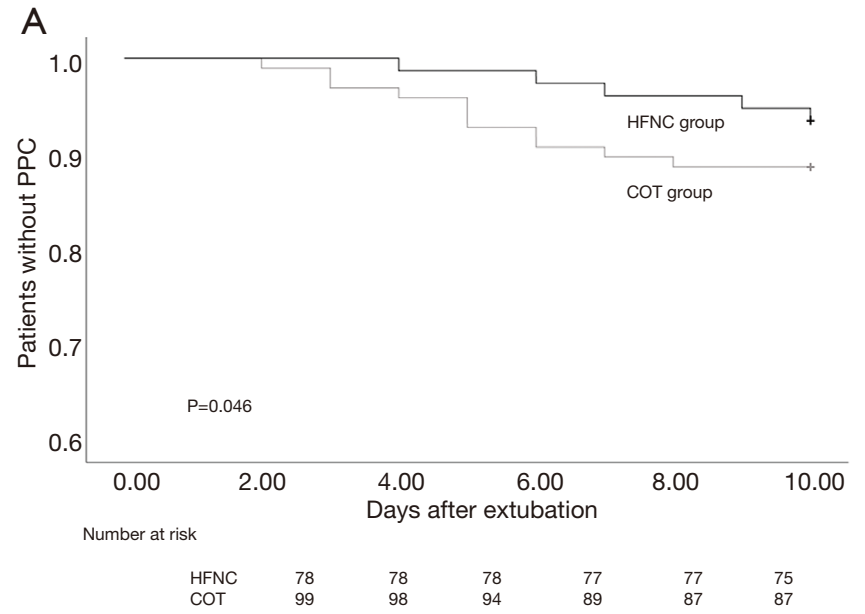

B

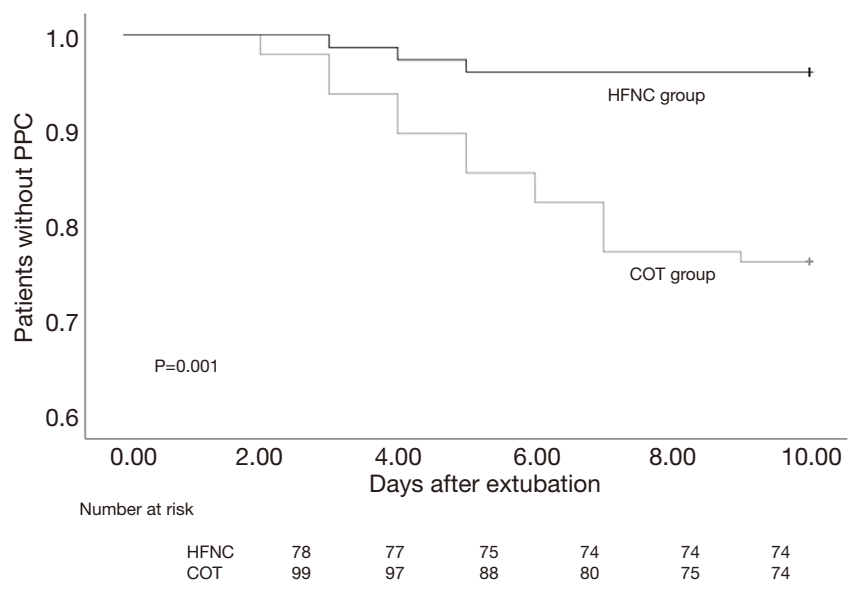

Figure 3 Kaplan-Meier plots of patients without anastomotic fistula or PPCs from post-operation to day 10. (A) Anastomotic fistula; (B) PPCs. HFNC, high-flow nasal cannula; COT, conventional oxygen therapy; PPC, postoperative pulmonary complication.

occurred in 3 out of 78 (3.8\%, 95\% CI: 9.810-10.062\%) patients in the HFNC group $(\mathrm{P}<0.05, \log$-rank test $)$ (Figure 3).

\section{Image reconstruction and volume calculation}

Compared to COT, HFNC treatment significantly decreased the amount of lung volume loss caused by pneumothorax, atelectasis and pulmonary consolidation (Figure 4, Table 3).

\section{Discussion}

Although perioperative management of EC patients has gradually improved, the morbidity and mortality rates after esophagectomy still remained the highest among all solid tumor surgeries. Takeuchi et al. (8) reported that out of all 5,354 EC patients who underwent esophagectomy in 713 institutions in Japan, 15.4\% developed pneumonia, 13.3\% suffered from anastomotic leakage, the 30-day mortality rate was $1.2 \%$ (4.3\% in United Kingdom, 3.0\% in United States) and the operative mortality rate was $3.4 \%$. The respiratory complications are the most common cause of death with the incidence ranging from $19.3 \%$ to $44.4 \%$ (9). Several studies have shown that the mortality rate after esophagectomy was ranged from $3.8 \%$ to $5.8 \%$, and among these patients, $50-56 \%$ died from respiratory complications $(10,11)$; the incidence of respiratory complications was ranged from $22.9 \%$ to $38.9 \%$; and that of anastomotic leaks was $13 \%$ to $35 \%(12-15)$. These results suggest that post-esophagectomy treatment is not only a prevention of postoperative complications but also an appropriate management crucial to minimize mortality.

Throat or nasal pain seems correlated with high morbidity in COT $(12.96 \%)$ due to lack of proper humidity. COT, which includes nasal catheter or mask oxygen absorption, though is lighter and more comfortable than HFNC, could neither accurately deliver fine-tuned oxygen concentration nor heated and humidified gas (16), therefore only rendering limited auxiliary effect on patient's lung. Compared to HFNC therapy, COT caused a higher degree of throat or nasal pain (12.96\%) due to its inability to deliver oxygen at a suitable level. In contrast, HFNC provides precise fractional oxygen delivery, a mild-level of positive airway pressure, washout of nasopharyngeal dead space, and a reduced airway resistance (17) and has advantages over other non-invasive ventilation therapy in easier use and better comfortability (18). A randomized controlled trial (RCT) has shown that application of HFNC therapy in adult patients was associated with a lower reintubation rate compared with COT (19). According to the consensus of domestic experts in 2019 (20), HFNC should be applied to patients with mild to moderate hypoxemia $(100 \mathrm{mmHg} \leq$ $\mathrm{PaO}_{2} / \mathrm{FiO}_{2}<300 \mathrm{mmHg}$ ), no emergency tracheal intubation, and relatively stable vital signs. Therefore, we included patients who underwent radical esophagectomy and had $\mathrm{PaO}_{2} / \mathrm{FiO}_{2}<300 \mathrm{mmHg}$ after offline extubation. In the study of Roca et al. (21), HFNC had better comfortability, 

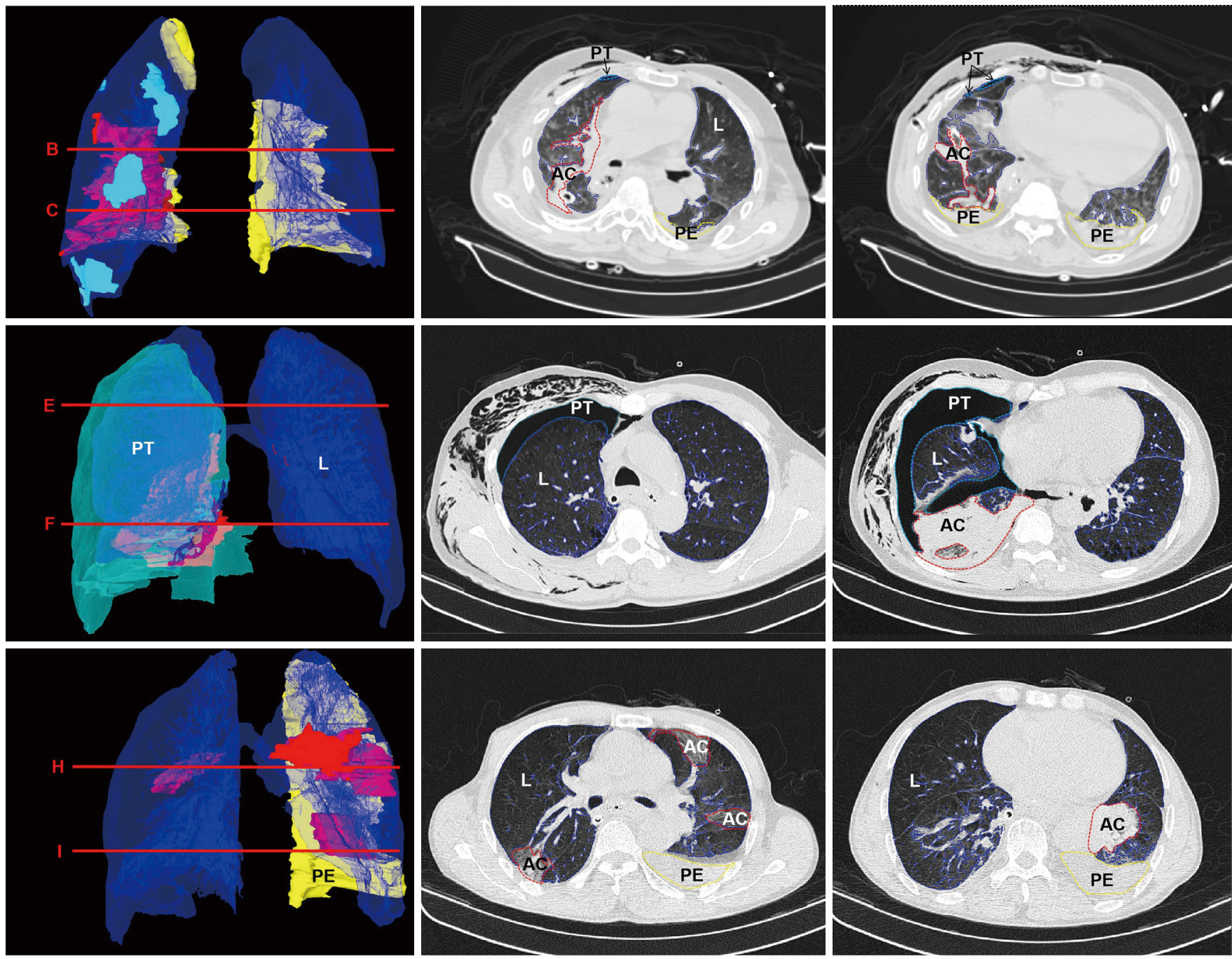

Lung

Ptelectasis and
consolidption Pneumothorax

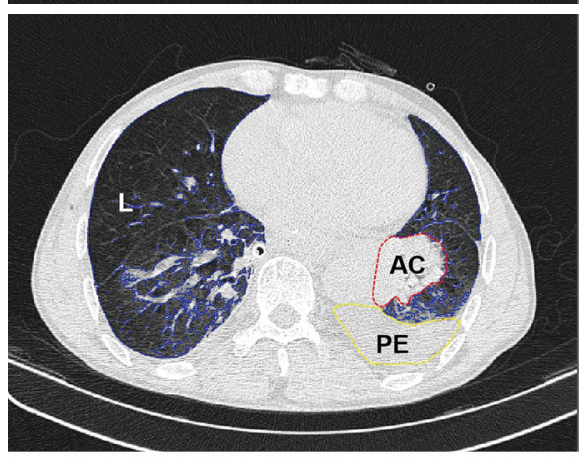

Pleural effussion

Figure 4 3D reconstruct the normal lung (L), pneumothorax (PT), pleural effusion (PE), atelectasis (AC) and lung consolidation, and pleural effusion.

Table 3 Comparison of the amount of lung volume loss between the HFNC and COT groups

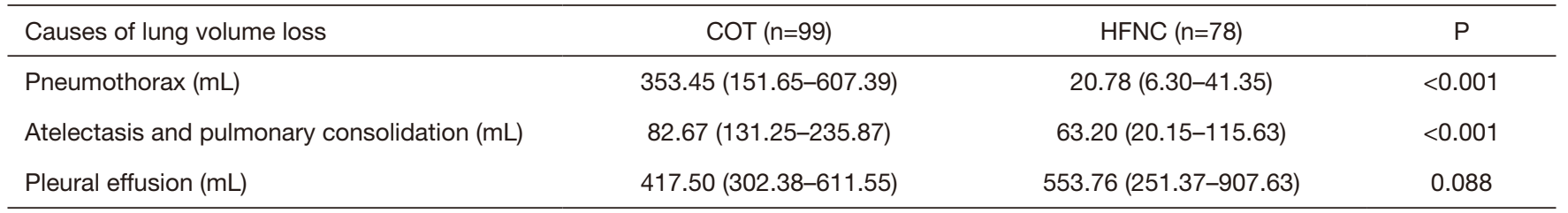

Data are expressed as median (IQR). HFNC, high-flow nasal cannula; COT, conventional oxygen therapy; IQR, interquartile range. 
significantly reduced breathing rate and higher oxygenation without significant differences in arterial blood $\mathrm{CO}_{2}$. Our results also showed that compared with patients in the COT group, patients in the HFNC group had significantly higher oxygenation, significantly lower hospital stay and better comfortability as indicated by lower incidence of nose pain and sore throat. All of these suggest that HFNC improves hypoxia and shortens the length of hospital stay. Sztrymf et al. (22) reported that HFNC could significantly reduce respiration rate and chest-abdominal asynchrony, and significantly improve $\mathrm{SaO}_{2} \%$. A retrospective study (23) reports on 75 patients with acute respiratory failure showed that HFNC treatment significantly improved a number of respiratory parameters within $24 \mathrm{~h}$ including $\mathrm{PaO}_{2}$, $\mathrm{SaO}_{2} \%$, RR and HR. A prospective study (24) evaluated the short-term physiological effects of HFNC by measuring parameters such as inspiratory muscle strength, gas exchange, dyspnea score, and comfort level and found that compared to COT, HFNC treatment significantly improved inspiratory power and oxygenation. In this study, the average RR of HFNC group was lower than that of COT group, but there was no significant difference. It may be due to the different disease types (after EC surgery), other factors affecting respiration (such as pain, thoracotomy, etc.), or the insufficient sample size. Compared to COT, HFNC treatment significantly decreased $\mathrm{BP}$ and $\mathrm{HR}$, increased $\mathrm{PaO}_{2}$ and $\mathrm{SaO}_{2} \%$. After EC surgery, $\mathrm{BP}$ is often higher than that before operation. The main causes are hypoxia and pain (active expectoration aggravates pain). HFNC can relieve hypoxia, humidify airway, and make sputum easier to be eliminated, thus reducing the pain caused by cough, which may be the reason for lowering BP.

In adults, PPCs are associated with both high mortality and extended ICU stays (25). PPCs are the development of at least one of the following symptoms within 7-30 postoperative days: atelectasis, respiratory failure, pleural effusion, pneumothorax, bronchospasm, respiratory infection, aspiration pneumonitis, and acute respiratory distress syndrome. The main reasons for the occurrence of PPCs are as follows. First, studies have shown that patients undergoing esophagectomy after preoperative chemoradiotherapy were afflicted with more severe respiratory complications and higher operative mortality rate than patients undergoing esophagectomy alone (26). Second, the cause of respiratory complications is multifactorial, such as postoperative minor aspirations, increased fluid load, multiple red cell transfusions, smoking, and genetic susceptibility. In addition, prolonged use of single lung ventilation during esophagectomy may also cause lung injury (27). Patients with squamous cell carcinoma also exhibited a higher incidence of pneumonia and respiratory insufficiency, altogether resulting in twice the overall rate of incidence than that of patients with adenocarcinoma (28). At last, pulmonary function tests may aid in the identification of high-risk patients beyond typical risk factors. In this regard, many studies have incorporated $\mathrm{FEV}_{1}$ as a predictor for postoperative complications after esophagectomy. In this study, no significant differences in preoperative $\mathrm{FEV}_{1}$ were found between the patients in HFNC and COT groups, inferring that the difference in PPCs between the two groups was not related to preoperative $\mathrm{FEV}_{1}$. Several possible reasons might explain why the within 10 days post-operation, patients suffering from hypoxemia after extubation in COT group suffered more complications than in HFNC group. First, HFNC promotes the removal of bronchial secretions by heating and humidifying oxygen so that it reaches the physiologically required temperature and humidity, which in turn is conducive to the recovery of the ciliary system and the active discharge of sputum (29). This is also validated by our findings that the sputum drainage volume of patients in the HFNC group was significant higher than that in the COT group $(\mathrm{P}<0.05)$. All patients in this study suffered from squamous cell carcinoma, inferring that they are inherently more prone to develop PPCs. Though in this case, the chances should be equal between the two groups. Research has shown that for every $10 \mathrm{~L} / \mathrm{min}$ increase in HFNC flow rate, patients' pharyngeal positive endexpiratory pressure (PEEP) increases by $0.5-1 \mathrm{cmH}_{2} \mathrm{O}$ and when the flow rate is increased to $60 \mathrm{~L} / \mathrm{min}$, the PEEP of the closed oropharyngeal cavities reaches $4-4.7 \mathrm{cmH}_{2} \mathrm{O}$ (30), thereby promoting oxygenation and lung recruitment and improving minute atelectasis. Predictors of anastomotic fistula are advanced age, preoperative chemoradiotherapy, poor physical status, low preoperative serum albumin level, pre-existing diabetes, high pathological stage and low pulmonary function. However, not one study has considered whether the difference in postoperative oxygen therapy was related to anastomotic leakage. Therefore, it is crucial to, after excluding preoperative risk factors, conduct careful and multidisciplinary assessment when administering postoperative oxygen therapy to EC patients. With regard to the pre-operative conditions of patients in the two groups, no significant difference was observed. However, patients in the HFNC group exhibited significantly lower incidence of anastomotic leakage. Factors such as smoking, anastomotic 
blood supply, perioperative nutritional status, preoperative chemoradiotherapy, hypoxia and pulmonary infection can lead to anastomotic leak after esophagectomy (31-33). In our study, HFNC can significantly improve blood oxygen after esophagectomy and reduce the incidence of pulmonary infection, which may be the reason for the decreased incidence of anastomotic leaks in the HFNC group.

\section{Conclusions}

Compared to lung cancer surgery, EC surgery takes longer time and is more invasive. Thus, it often leads to more postoperative complications including hypoxemia (34). The sequential treatment of mild to moderate postoperative hypoxemia with HFNC oxygen therapy effectively improves patients' oxygenation, reduces the incidence of clinical PPC and anastomotic leakage, shortens the length of hospital stay, and promotes patients' recovery and discharge. A large prospective randomized trial would be required to determine whether the modalities of post-extubation oxygen therapy influence weaning success or failure.

\section{Acknowledgments}

Funding: This work was supported by the National Natural Science Foundation of China (No. 31771324; http:// www. nsfc.gov.cn/), Chongqing basic research and frontier exploration project (No. cstc2018jcyjAX0537), University Funded Science and Technology Innovation Capacity Improvement Project (No. 2019XYY14).

\section{Footnote}

Reporting Checklist: The authors have completed the STROBE reporting checklist. Available at http://dx.doi. org/10.21037/apm-20-1539

Data Sharing Statement: Available at http://dx.doi. org/10.21037/apm-20-1539

Conflicts of Interest: All authors have completed the ICMJE uniform disclosure form (available at http://dx.doi. org/10.21037/apm-20-1539). The authors have no conflicts of interest to declare.

Ethical Statement: The study was conducted in accordance with the Declaration of Helsinki (as revised in 2013). The study was approved by the Ethical Committee of Southwest
Hospital (IRB number: KY201846) and individual consent for this retrospective analysis was waived. The authors are accountable for all aspects of the work in ensuring that questions related to the accuracy or integrity of any part of the work are appropriately investigated and resolved.

Open Access Statement: This is an Open Access article distributed in accordance with the Creative Commons Attribution-NonCommercial-NoDerivs 4.0 International License (CC BY-NC-ND 4.0), which permits the noncommercial replication and distribution of the article with the strict proviso that no changes or edits are made and the original work is properly cited (including links to both the formal publication through the relevant DOI and the license). See: https://creativecommons.org/licenses/by-nc-nd/4.0/.

\section{References}

1. Rustgi AK, El-Serag HB. Esophageal carcinoma. N Engl J Med 2014;371:2499-509.

2. Pennathur A, Gibson MK, Jobe BA, et al. Oesophageal carcinoma. Lancet 2013;381:400-12.

3. Song Y, Li L, Ou Y, et al. Identification of genomic alterations in oesophageal squamous cell cancer. Nature 2014;509:91-5.

4. Torre LA, Bray F, Siegel RL, et al. Global cancer statistics, 2012. CA Cancer J Clin 2015;65:87-108.

5. Wang J, Zhang B, Meng J, et al. Analysis of risk factors for post-operative complications and prognostic predictors of disease recurrence following definitive treatment of patients with esophageal cancer from two medical centers in Northwest China. Exp Ther Med 2017;14:2584-94.

6. Pennisi MA, Bello G, Congedo MT, et al. Early nasal high-flow versus Venturi mask oxygen therapy after lung resection: a randomized trial. Crit Care 2019;23:68.

7. Li J, Jing G, Scott JB. Year in review 2019: high-flow nasal cannula oxygen therapy for adult subjects. Respir Care 2020;65:545-57.

8. Takeuchi H, Miyata H, Gotoh M, et al. A risk model for esophagectomy using data of 5354 patients included in a Japanese nationwide web-based database. Ann Surg 2014;260:259-66.

9. Ferguson MK, Durkin AE. Preoperative prediction of the risk of pulmonary complications after esophagectomy for cancer. J Thorac Cardiovasc Surg 2002;123:661-9.

10. Ott K, Bader FG, Lordick F, et al. Surgical factors influence the outcome after Ivor-Lewis esophagectomy with intrathoracic anastomosis for adenocarcinoma of 
the esophagogastric junction: a consecutive series of 240 patients at an experienced center. Ann Surg Oncol 2009; 16:1017-25.

11. Atkins BZ, Shah AS, Hutcheson KA, et al. Reducing hospital morbidity and mortality following esophagectomy. Ann Thorac Surg 2004;78:1170-6.

12. Baba M, Aikou T, Yoshinaka H, et al. Long-term results of subtotal esophagectomy with three-field lymphadenectomy for carcinoma of the thoracic esophagus. Ann Surg 1994;219:310-6.

13. Wiedemann HP, Wheeler AP, Bernard GR, et al. Comparison of two fluid-management strategies in acute lung injury. N Engl J Med 2006;354:2564-75.

14. Blencowe NS, Strong S, McNair AG, et al. Reporting of short-term clinical outcomes after esophagectomy: a systematic review. Ann Surg 2012;25 5:658-66.

15. Takeuchi H, Miyata H, Gotoh $M$, et al. A risk model for esophagectomy using data of 5354 patients included in a Japanese Nationwide Web-Based Database. Ann Surg 2014;260:259-66.

16. Lee JH, Rehder KJ, Williford L, et al. Use of high flow nasal cannula in critically ill infants, children, and adults: a critical review of the literature. Intensive Care Med 2013;39:247-57.

17. Rubin S, Ghuman A, Deakers T, et al. Effort of breathing in children receiving high-flow nasal cannula. Pediatr Crit Care Med 2014;15:1-6.

18. Manley BJ, Owen L, Doyle LW, et al. High-flow nasal cannulae and nasal continuous positive airway pressure use in non-tertiary special care nurseries in Australia and New Zealand. J Paediatr Child Health 2012;48:16-21.

19. Hernández G, Vaquero C, González P, et al. Effect of postextubation high-flow nasal cannula vs conventional oxygen therapy on reintubation in low-risk patients: a randomized clinical trial. JAMA 2016;315:1354-61.

20. Xu JQ, Su LX, Yan P, et al. Expert consensus on clinical standardized application of high-flow nasal cannula oxygen therapy in adults. Chin Med J (Engl) 2020;133:1322-4.

21. Roca O, Riera J, Torres F, et al. High-flow oxygen therapy in acute respiratory failure. Respir Care 2010;5 5:408-13.

22. Sztrymf B, Messika J, Bertrand F, et al. Beneficial effects of humidified high flow nasal oxygen in critical care patients: a prospective pilot study. Intensive Care Med 2011;37:1780-6.

23. Hyun Cho W, Ju Yeo H, Hoon Yoon S, et al. High-flow nasal cannula therapy for acute hypoxemic respiratory failure in adults: a retrospective analysis. Intern Med 2015;54:2307-13.
24. Vargas F, Saint-Leger M, Boyer A, et al. Physiologic effects of high-flow nasal cannula oxygen in critical care subjects. Respir Care 2015;60:1369-76.

25. Fernandez-Bustamante A, Frendl G, Sprung J, et al. Postoperative pulmonary complications, early mortality, and hospital stay following noncardiothoracic surgery: a multicenter study by the Perioperative Research Network Investigators. JAMA Surg 2017;152:157-66.

26. Bosset JF, Gignoux M, Triboulet JP, et al. Chemoradiotherapy followed by surgery compared with surgery alone in squamous-cell cancer of the esophagus. $\mathrm{N}$ Engl J Med 1997;337:161-7.

27. Tandon S, Batchelor A, Bullock R, et al. Peri-operative risk factors for acute lung injury after elective oesophagectomy. Br J Anaesth 2001;86:633-8.

28. Im Y, Park HY, Shin S, et al. Prevalence of and risk factors for pulmonary complications after curative resection in otherwise healthy elderly patients with early stage lung cancer. Respir Res 2019;20:136.

29. Zhang J, Lin L, Pan K, et al. High-flow nasal cannula therapy for adult patients. J Int Med Res 2016;44:1200-11.

30. Zochios V, Klein AA, Jones N, et al. Effect of high-flow nasal oxygen on pulmonary complications and outcomes after adult cardiothoracic surgery: a qualitative review. J Cardiothorac Vasc Anesth 2016;30:1379-85.

31. Van Daele E, Van Nieuwenhove Y, Ceelen W, et al. Assessment of graft perfusion and oxygenation for improved outcome in esophageal cancer surgery: protocol for a single-center prospective observational study. Medicine 2018;97:e12073.

32. Kitayama J, Kaisaki S, Ishigami H, et al. Angleplasty in gastric tube reconstruction after esophagectomy. Dis Esophagus 2009;22:418-21.

33. Li H, Wang D, Wei W, et al. The predictive value of coefficient of PCT x BG for anastomotic leak in esophageal carcinoma patients with ARDS after esophagectomy. J Intensive Care Med 2019;34:572-7.

34. Watanabe I, Fujihara H, Sato K, et al. Beneficial effect of a prone position for patients with hypoxemia after transthoracic esophagectomy. Crit Care Med 2002;30:1799-802.

Cite this article as: Xia M, Li W, Yao J, Jin Y, Du G, Xu Q, Yi X, Nv X, Wu Y, He P, Wu W. A postoperative comparison of highflow nasal cannula therapy and conventional oxygen therapy for esophageal cancer patients. Ann Palliat Med 2021;10(3):2530-2539. doi: 10.21037/apm-20-1539 